\title{
Is coronary artery bypass surgery riskier in female?*
}

\author{
Habib Cakir ${ }^{1 \#}$, Hasan Uncu ${ }^{2}$, Ozcan Gur ${ }^{3}$, Mehmet Acipayam ${ }^{4}$, Ismail Yurekli ${ }^{1}$, Ozsoyler Ibrahim $^{2}$ \\ ${ }^{1}$ Cardiovascular Surgeon, Cardiovascular Surgery, Katip Celebi University Ataturk Education and Training Hospital, Izmir, Turkey \\ ${ }^{2}$ Cardiovascular Surgeon, Cardiovascular Surgery, Adana Numune Education and Training Hospital, Adana, Turkey \\ ${ }^{3}$ Cardiovascular Surgeon, Cardiovascular Surgery, Namik Kemal University Medicine Faculty, Tekirdag, Turkey \\ ${ }^{4}$ Cardiovascular Surgeon, Cardiovascular Surgery, Mustafa Kemal University Medicine Faculty, Antakya and İskenderun, Turkey \\ Email: "
}

Received 15 September 2012; revised 18 October 2012; accepted 28 October 2012

\begin{abstract}
Introduction: In this study we examined the early results of coronary artery bypass surgery in our female patients and compared them with those of our male patients. Material and Methods: One thousand and ninety four patients who underwent coronary artery bypass surgery between January 2009 and December 2011 in our clinic were included into this study. Three hundred and thirteen female patients (group 1) were compared to $\mathbf{7 8 1}$ male patients (group 2). Results: The mean age of group 1 was $61.4 \pm 9.6$, and the mean age of group 2 was $58.1 \pm 9.6$ (p< $0.001)$. The ratio of diabetes mellitus and hypertension in group 1 was higher than that of group $2(p<$ 0.001). There were no significant difference between two groups when compared regarding the need for inotropics after weaning from cardiopulmonary bypass, cross clamp and total cardiopulmonary bypass periods $(p>0.05)$. It was found that the amount of drainage was higher in group 1 than group $2(p<$ 0.001). There was no significant difference between two groups when compared in terms of mortality, reoperation (because of bleeding), postoperative atrial fibrillation, need for intraaortic balloon pump, usage of levosimendan, cerebrovascular accident, chronic renal failure, discharging intervals and period in intensive care unit. It was found that sternal wound infection was higher in group 1 than group $2(p<$ 0.05). Conclusion: We consider that female gender does not put an additional risk to increase mortality and morbidity in coronary artery bypass surgery.
\end{abstract}

Keywords: Female; Mortality; Coronary Artery Bypass Graft Surgery

\section{INTRODUCTION}

Coronary artery bypass surgery is an effective and reli-

\footnotetext{
"Our study is a retrospective study of a single center.

\#Corresponding author.
}

able method in coronary artery disease. The leading cause of death is ischemic heart disease in female patients like in male patients. The incidence of ischemic heart disease has increased in female patients recently [1]. It is speculated that female sex is an independent risk factor for mortality in isolated coronary artery bypass surgery. Some authors postulated that female gender is an independent risk factor for mortality, whereas some others postulated the opposite [2,3].

In this study we examined the early results of coronary artery bypass surgery in our female patients and compared them with those of our male patients.

\section{MATERIAL AND METHODS}

One thousand and ninety four patients who underwent coronary artery bypass surgery between January 2009 and December 2011 in our clinic were included into this study. Patients demanding carotid or valvular surgery were excluded from study. Three hundred and thirteen female patients (group 1) were compared to 781 male patients (group 2). Routine transthoracic echocardiography was carried out in all patients before surgery and the ejection fraction was calculated by Simpsons method. For induction of anesthesia, fentanyl citrate (Fentanyl Citrate, Abott) and midazolame (Dormicum, Roche) were used. In addition, sevofluorane (Sevorane, Abott) and vercuronium bromide (Norcuron, Organon) were used for maintanence. Coronary artery bypass graft was applied either on the beating heart or under cardiopulmonary bypass. $2 \mathrm{mg} / \mathrm{kg}$ Heparin (Nevparin, Mustafa Nevzat) was used in beating heart operations and $4 \mathrm{mg} / \mathrm{kg}$ heparin was used for cardiopulmonary bypass operations. In operations under cardiopulmonary bypass, mild systemic hypothermia was applied and cardiac arrest was maintained by warm blood cardioplegia given through the aortic root antegradely. Cardioplegia given through the aortic root was repeated in every 20 minutes throughout cardiopulmonary bypass. Antegrade cardioplegia was given through the proximal end of the saphenous vein grafts after each distal anastomosis of saphenous vein 
grafts. Proximal anastomosis was done under side clamps. Neutralisation of heparin was maintained by protamine hydrochloride (Protamine ICN, Onko) in a ratio of $1: 1$. Demographic properties of the patients, operational data and postoperative complications were registered. Patients that needed permanent hemodialysis postoperatively were considered as having chronic renal failure.

\section{STATISTICAL ANALYSIS}

SPSS 18.0 program was used in analyzing the data statistically. Qualitative data were summarized as numbers and percentage; quantitative data were summarized as mean and standard deviation (if necessary as mean, minimum, and maximum). Chi square test was used to compare the quantitative values between two groups. In comparing quantitative data between binary groups t-test was used in hypothetical groups and Mann Whitney U test was used in non-hypothetical groups. In comparing numerical measurements of more than two groups one way variance analysis was used for hypothetical ones and Kruskal Wallis test is used for non-hypothetical ones. Logistic regression analysis was used to define the parameters that had an impact on mortality. $\mathrm{p}<0.05$ was considered as significant.

\section{RESULTS}

It was detected that the frequency of female patients was 28.6\% among 1094 patients undergoing isolated coronary artery bypass surgery. The mean age of group 1 was $61.4 \pm 9.6$, and the mean age of group 2 was $58.1 \pm 9.6$ $(\mathrm{p}<0.001)$. The ratio of diabetes mellitus and hypertension in group 1 was higher than that of group 2 ( $p<$ 0.001 ). There was no significant difference between two groups when compared for chronic obstructive pulmonary disease (COPD), ejection fraction and use of left internal mammary artery $(\mathrm{p}=0.490, \mathrm{p}=0.162, \mathrm{p}=$ 0.291). Preoperative demographic features of patients were listed in Table 1. Coronary artery bypass surgery was carried out on beating heart in 23 patients in group 1 and in 50 patients in group $2(p=0.592)$. There were no significant difference between two groups when compared regarding the need for inotropics after weaning from cardiopulmonary bypass, cross clamp and total cardiopulmonary bypass periods $(\mathrm{p}=0.323, \mathrm{p}=0.334, \mathrm{p}=$ $0.745)$. It was found that the amount of drainage was higher in group 1 than group $2(p<0.001)$. There was no significant difference between two groups when compared in terms of re-operation (because of bleeding), postoperative atrial fibrillation, need for intraaortic balloon pump, usage of levosimendan, cerebrovascular accident, chronic renal failure, discharging intervals and period in intensive care unit $(\mathrm{p}=0.240, \mathrm{p}=0.094, \mathrm{p}=$ $0.422, \mathrm{p}=0.370, \mathrm{p}=0.491, \mathrm{p}=0.491, \mathrm{p}=0.084, \mathrm{p}=$
0.116). It was found that sternal wound infection was higher in group 1 than group $2(\mathrm{p}<0.05)$. Mortality rates were $1.9 \%$ in group 1 and $1.6 \%$ in group $2(p=0.799)$. Postoperative findings and data are listed in Table 2. As the result of multivariant analyses performed for mortality, gender had no effect on mortality $(p>0.05)$. The most important parameters that affected mortality were cardiopulmonary bypass time ( $\mathrm{p}<0.001$, OR $1.024,95 \%$ $\mathrm{CI})$ and use of intraaortic balloon pump ( $\mathrm{p}=0.002$, OR $10.512,95 \% \mathrm{CI})$.

\section{DISCUSSION}

Coronary artery disease is generally seen about 10 years later in female population when compared to males [1]. But it was evident that the incidence of premenopausal coronary artery disease has increased in females recently because of smoking [4]. In our study, it was detected that the mean age of female patients was 61.5 and the mean age of male patients was 58 . This age difference is becoming smaller and smaller as years pass by. In some studies, the frequency of female patients has been reported to be between $24 \%$ and $30 \%$ in coronary artery bypass surgery $[5,6]$. In our study, it was detected that the frequency of female patients was $28.6 \%$. We consider that the frequency of female patients undergoing bypass

Table 1. Preoperative demographic findings.

\begin{tabular}{cccc}
\hline & group 1 $(\mathrm{n}=313)$ & group 2 $(\mathrm{n}=781)$ & $\mathrm{p}$ \\
\hline Age & $61.4 \pm 9.6$ & $58.1 \pm 9.6$ & $<\mathbf{0 . 0 5}$ \\
Hypertension & 201 & 264 & $<\mathbf{0 . 0 5}$ \\
Diabetes Mellitus & 144 & 206 & $<\mathbf{0 . 0 5}$ \\
COPD & 22 & 46 & $>0.05$ \\
EF & $48.8 \pm 18.1$ & $45.8 \pm 19$ & $>0.05$ \\
Use of LIMA & 278 & 710 & $>0.05$ \\
\hline
\end{tabular}

COPD: Chronic obstructive pulmonary disease, EF: Ejection fraction, LIMA: Left internal mammary artery.

Table 2. Postoperative findings and data.

\begin{tabular}{|c|c|c|c|}
\hline & group $1(n=313)$ & group $2(n=781)$ & $\mathrm{p}$ \\
\hline Drainage (ml) & $475.7 \pm 388.9$ & $683 \pm 432.5$ & $<\mathbf{0 . 0 5}$ \\
\hline Revision & 6 & 27 & $>0.05$ \\
\hline CVA & 1 & 1 & $>0.05$ \\
\hline $\begin{array}{c}\text { Discharging } \\
\text { intervals (day) }\end{array}$ & $8.3 \pm 3.3$ & $7.1 \pm 2.7$ & $>0.05$ \\
\hline $\begin{array}{l}\text { Sternal wound } \\
\text { infection }\end{array}$ & 11 & 3 & $<0.05$ \\
\hline $\begin{array}{l}\text { Chronic kidney } \\
\text { failure }\end{array}$ & 1 & 1 & $>0.05$ \\
\hline Exitus & 6 & 13 & $>0.05$ \\
\hline
\end{tabular}

CVA: Cerebrovascular accident. 
surgery did not change in years.

The prevalence of diabetes mellitus is usually higher in female patients [7]. In some studies, it has been reported that the rate of diabetes mellitus, age and hypertension were higher in female patients than male patients [6-8]. In our study, it was detected that the rates of diabetes mellitus and hypertension were higher in female patients than that of male patients. When compared in terms of wound infection after coronary artery bypass surgery, female patients have more risk than male patients [8]. In our study, it was seen that the sternal wound infection was more common in female patients than in male patients. Diabetes mellitus is an independent risk factor for sternal wound infection after coronary artery bypass surgery [9]. The higher rate of sternal wound infection in female patients might be explained with the higher prevalence of diabetes mellitus in this group.

Aldea et al. have been reported that need for inotropics after weaning from cardiopulmonary bypass was higher and hospital stay was longer in female patients undergoing coronary artery bypass surgery [6]. Alike, Alam et al. have been reported that duration of hospital stay was longer in female patients [2]. In our study, there was no difference between two groups in terms of need for inotropic support after weaning from cardiopulmonary bypass and duration of hospital stay. In a study, it was detected that the incidence of atrial fibrillation was lower in female patients [2]. In our study, there is no significant difference between two groups in terms of incidence of atrial fibrillation. In Goksedef et al.'s study, it was detected that the rate of re-operation (because of bleeding) was higher in male patients than in female patients [5]. In Parolari et al.'s study, it was detected that the amount of drainage and the rate of re-operation were lower in female patients than in male patients [10]. In our study, although the amount of drainage was less in female patients, there was no difference between two groups in terms of reoperation for bleeding

It is speculated that female gender is an independent risk factor for mortality in isolated coronary artery bypass surgery. Some studies support this opinion $[2,5]$, but some studies do not $[3,6]$. In our study, although mortality rates were higher in female patients, there was no significant difference found. We consider that female gender is not an independent risk factor for mortality in isolated coronary artery bypass surgery because of improving technology and progressing surgical skills when compared to previous years.

\section{CONCLUSION}

Preoperative demographic findings are different among female and male patients. We consider that female gender does not put an additional risk to increase mortality and morbidity in coronary artery bypass surgery.

\section{ACKNOWLEDGEMENTS}

We hereby like to thank Dr. Serkan Ketenciler for his participation in English editing.

\section{REFERENCES}

[1] Kayikcioglu, M., (2010) Ischemic heart disease in women. Archives of the Turkish Society of Cardiology, 38, 41-49.

[2] Alam, M., Lee, V.V., Elayda, M.A., Shahzad, S.A., Yang, E.Y., Nambi, V., et al. (2012) Association of gender with morbidity and mortality after isolated coronary artery bypass grafting. A propensity score matched analysis. International Journal of Cardiology. doi:10.1016/j.ijcard.2011.12.047

[3] Koch, C.G., Khandwala, F., Nussmeier, N. and Blackstone, E.H. (2003) Gender and outcomes after coronary artery bypass grafting: A propensity-matched comparison. The Journal of Thoracic and Cardiovascular Surgery, 126, 2032-2043. doi:10.1016/S0022-5223(03)00950-4

[4] Ford, E.S. and Capewell, S. (2007) Coronary heart disease mortality among young adults in the US from 1980 through 2002: Concealed leveling of mortality rates. Journal of the American College of Cardiology, 50, 21282132. doi:10.1016/i.jacc.2007.05.056

[5] Goksedef, D., Omeroglu, N.S., Balkanay, O.O., Talas, Z., Arapi, B. and Ipek, G. (2012) Coronary artery bypass in women: What is really different? Türk Göğ̈̈s Kalp Damar Cerrahisi Dergisi, 1, 8-13.

[6] Aldea, G.S., Gaudiani, J.M., Shapira, O.M., Jacobs, A.K., Weinberg, J., Cupples, A.L., et al. (1999) Effect of gender on postoperative outcomes and hospital stays after coronary artery bypass grafting. The Annals of Thoracic Surgery, 67, 1097-1103. doi:10.1016/S0003-4975(99)00055-7

[7] Spencer, E.A., Pirie, K.L., Stevens, R.J., Beral, V., Brown, A., Liu, B., et al. (2008) Million women study collaborators. Diabetes and modifiable risk factors for cardiovascular disease: The prospective million women Study. European Journal of Epidemiology, 23, 793-799. doi:10.1007/s10654-008-9298-3

[8] Saxena, A., Dinh, D., Smith, J.A., Shardey, G., Reid, C.M. and Newcomb, A.E. (2012) Sex differences in outcomes following isolated coronary artery bypass graft surgery in Australian patients: Analysis of the Australasian Society of Cardiac and Thoracic Surgeons cardiac surgery database. European Journal Cardio-Thoracic Surgery, 41, 755-762. doi:10.1093/ejcts/ezr039

[9] Fakih, M.G., Sharma, M., Khatib, R., Berriel-Cass, D., Meisner, S., Harrington, S, et al. (2007) Increase in the rate of sternal surgical site infection after coronary artery bypass graft: A marker of higher severity of illness. Infection Control and Hospital Epidemiology, 28, 655-660. doi:10.1086/518347

[10] Parolari, A., Dainese, L., Naliato, M., Polvani, G., Loardi, C., Trezzi, M., et al. (2008) Do women currently receive the same standard of care in coronary artery bypass graft procedures as men? A propensity analysis. The Annals of Thoracic Surgery, 85, 885-890. doi:10.1016/j.athoracsur.2007.11.022 